\title{
LINEAR DIFFERENTIAL OPERATORS
}

CORNELIUS LANCZOS, Senior Professor, School of Theoretical Physics, Dublin Institute for Advanced Studies

This book deals thoroughly with certain new and advanced topics in mathematical analysis, and is likely to interest engineers, mathematical physicists and other applied mathematicians. By examining the properties of certain mathematical entities, notably the Green's function. Professor Lanczos conducts a broad investigation into linear differential operators, taking as his central theme the identity of form and treatment between these operators and matrix algebra.

$6 \times 9,582$ pages, 58 diagrams, 3 tables, price 80 s.

\section{ADVANCED CALCULUS}

\section{H. K. NICKERSON; D. E. SPENCER AND N. E. STEENROD.}

This unusual book is an attempt to bring the honours student in mathematics to grips with underlying mathematical ideas by getting away from lists of formulas and exercises. A unity is achieved by beginning with an abstract treatment of vector spaces and linear transformations. A single basic derivative (the Frechet derivative) is introduced in an invariant form. All other derivatives (velocity fields, gradients, divergences, curls and exterior derivatives) are obtained from it by specialisation. The corresponding theory of integration is likewise unified; the Stokes' and Green's theorems appear as special cases of generalised Stokes' formula concerning integration of exterior forms. A final chapter contains applications to the theory of analytical functions of complex variables.

$9 \times 11,540$ pp., varitype, loose spiral bound, $49 \mathrm{~s}$.

\section{FIELD THEORY FOR ENGINEERS}

PARRY MOON, Associate Professor Electrical Engineering, Massachusetts Institute of Technology.

DOMINA SPENCER, Associate Professor of Mathematics, University of Connecticut.

This book applies boundary-value techniques to engineering, and is the first reference volume specifically designed to explain field theory to advanced students and engineers. All aspects are covered, including electro-magnetic, acoustical, thermal and gravitational fields. The powerful technique of separation by variables has been employed as the principal method.

194 figs. 20 tables, $6 \times 9,540$ pp. 96 s.

\section{TRANSIENT CIRCUIT ANALYSIS}

Y H. KU, Senio. Member of the Institute of Radio Engineers; Prof. at the Moore School of

Electrical Engineering, University of Pennsylvania.

This book offers a broad treatment of transient circuit analysis from a combined Fourier and Laplace transform approach and is intended for senior undergraduate and post-graduate students in electrical or mechanical engineering.

115 illus., $6 \times 9,350 \mathrm{pp} ., 79 \mathrm{~s}$.

\section{CALCULUS: AN INTRODUCTORY APPROACH}

IVAN NIVEN, Prof. of Mathematics, University of Oregon. University Series in Undergraduate Mathematics.

A rapid, carefully graduated advance to the fundamentals of calculus for students with a background of algebra and a little trigonometry. By plunging at once into actual problems and developing the series expansions of trigonometric, logarithmic, and exponential functions without the elaborate preliminaries usual in texts, the author achieves a remarkable exposition in small compass.

56 illus., $6 \times 9,250$ pp., $36 \mathrm{~s}$.

\section{Van Nostrand}

358 Kensington High Strect, London W/4 
BRISTOL COLLEGE OF SCIENCE AND TECHNOLOGY

The Department of Mathematics

offers

a three-year sandwich course

leading to $a$

\section{COLLEGE DIPLOMA IN MATHEMATICS}

Both college-based and industry-based students are being accepted for this course, which starts in September. During the second and third years of the course students specialise in either APPLIED MATHEMATICS or STATISTICS. Pure Mathematics and Numerical Analysis are studied throughout, together with practical experience on the department's digital and analogue computers.

Applications for admission to the course should be made as soon as possible to the Registrar, Bristol College of Science and Technology, Ashley Down, Bristol, 7, from whom further information may be obtained. 


\section{HOW TO READ STATISTICS}

I R. VESSELO, M.Ed., B.Sc., Principal Lecturer in Mathematics, Cheshire County Training College, Alsager.

The aim of this book is to present the elements of statistical method in such a manner as to induce a critical attitude towards the conclusions drawn from numerical and graphical data. The subjects dealt with include chance, averages, dispersion, correlation and sampling.

Most elementary works on this subject are concerned mainly with the technique of calculation, as a branch of applied mathematics. In this book, though the calculations have not been neglected, the emphasis is on the results of the calculations and their implication.

Ready Early 1962.

About 10s. 6d. net

\section{CALCULUS}

D. R. DICKINSON, M.A., Ph.D., Head of the Mathematical Department, Bristol Grammar School.

"His book demands comparison with the best of its kind and it stands up well to the comparison."-The Times Educational Supplement. "The first volume covers a very good G.C.E. 'A' level course . the second volume carries the work beyond ' $S$ ' level.. These carefully written and very readable books will surely be welcomed in our schools."-Technical Journal.

With answers.

Vol. 1, 17s. 6d. Vol. 2, 13s. 6d.

\section{AN INTRODUCTORY COURSE IN PURE MATHEMATICS}

K. B. SWAINE, M.A., Head of the Mathematics Department, Yeovil School.

This book is a continuation of the author's Exercises in Elementary Mathematics. It provides a VIth form course in Pure Mathematics to advanced and scholarship levels for science students, or to advanced level for mathematical specialists. "This volume is a work of thorough professional craftsmanship, which teachers will enjoy."-Mathematical Gazette.

With answers.

15s.

GEORGE G. HARRAP \& CO. LTD

182 High Holborn, London W.C.1 


\section{Analogue Computer}

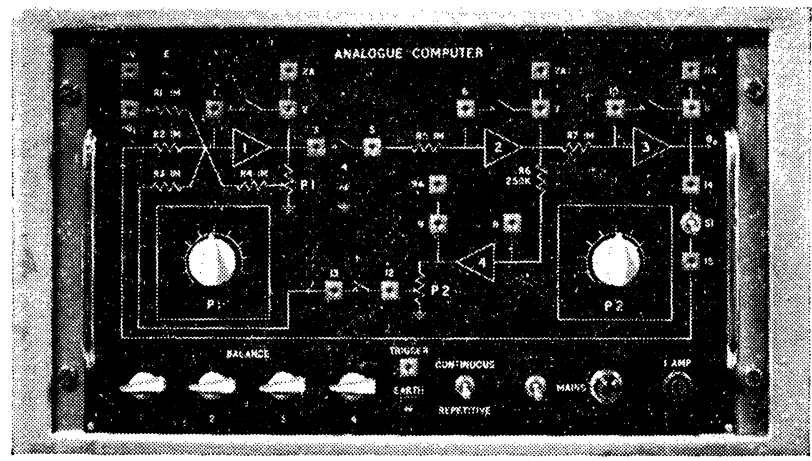

This instrument provides a first introduction to the practical aspects of analogue computation, such as scaling and the choice of time-constants, without the complexity of a full-scale computer. It is primarily intended for use by students in the engineering departments of Universities and Technical Colleges but would also be extremely valuable as a demonstration aid for mathematics students in the Sixth Form of Schools. Solutions may be displayed on any simple cathode-ray oscilloscope (an afterglow screen is not required).

Containing four amplifiers, it permits the solution of linear differential equations of up to the third order and the simulation of any dynamical system described by such equations. For example, it is eminently suitable for studying all the basic methods of stabilising servomechanisms. With additional networks and non-linear circuits, higher order and non-linear equations may be studied. It works either repetitively at $25 \mathrm{c} / \mathrm{s}$, for the study of transient responses or continuously when it may be used in conjunction with any simple audio-frequency oscillator for the study of resonance responses.

\section{F. C. ROBINSON \& PARTNERS LIMITED}

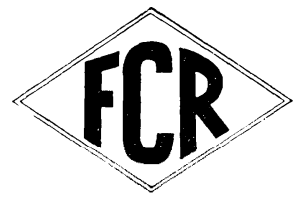

Specialists in Instrumentation

COUNCILLOR LANE, CHEADLE, CHESHIRE

Telephone: Gatley $2469 / 4020$ 


\section{Diploma Course in Technological Mathematics}

Battersea College of Technology, London, S.W.11, offers fulltime sandwich courses leading to the Diploma in Technology (Technological Mathematics). The course is of Honours Degree standard and is designed principally for men and women intending to make careers as mathematicians in industry or Government research institutions; it lasts four years, of which the third is spent in industrial training. The minimum entry qualification is two " $A$ " levels in mathematical subjects and/or physics with supplementary "O" levels.

Further particulars may be obtained from the Head of the Mathematics Department.

A NEW TWO-VOLUME WORK WHICH COVERS THE PURE MATHEMATICS REQUIRED FOR THE SCHOLARSHIP EXAMINATION OF THE UNIVERSITIES OF OXFORD AND CAMBRIDGE

\section{SCHOLARSHIP MATHEMATICS : Vol. I}

Analysis

By A. T Starr, M.A., Ph.D., M.I.E.E.

Abridged contents:-Real Variable-Complex Variable-Elementary Transcendental Functions-Differential Calculus-Integral Calculus. The book contains a number of worked and unworked examples and is illustrated where necessary with line drawings.

\section{SCHOLARSHIP MATHEMATICS : Vol. II Geometry \\ By A. T Starr, M.A., Ph.D., M.I.E.E.}

Abridged contents:-Advanced Euclid-Analytical Euclidean Geometry-Algebraic Projective Geometry. This book also contains a number of worked and unworked examples and many line drawings.

21/-

\section{PITMAN}




\title{
Abstract Sets and Finite Ordinals
}

G. B. KEENE, University of Exeter

In this book an attempt has been made to bring together the logical and philosophical aspects of set theory in such a way as to be intelligible both to mathematicians without training in formal logic and to logicians without a mathematical background. The author has combined an elementary level of treatment with the highest possible degree of logical rigour and precision.

21s. net $(\$ 3.50)$

\section{The Theory of Mathematical Machines}

Edited by Yu. Ya. BAZILEVSKII

The articles in this volume are all original works, and are based on experience gained by the authors in their investigations into the design and construction of new types of mathematical machines. They are devoted primarily to questions of logic and programming, and must prove invaluable to all scientists and engineers interested in this topical field of research.

Approx, 60s. (\$10.00)

\section{PERGAMON BOOKS}

吕 Convergence Problems of Orthogonal Series

G. ALEXITS

This volume gives a systematic account of the convergence theory of the orthogonal series. A revised and enlarged edition of the German original, it includes all the new and important discoveries of recent years and also shows the connection of the general theory with the corresponding questions of classical theory.

In preparation

\section{Introduction to Set Theory and Topology}

K. KURATOWSKI-Professor of Mathematics, University of Warsaw

This important volume is divided into two parts- the first covering basic material from the theory of sets and functions, and the second taking up fundamental topics in topology. The text is extended and new concepts are emphasized in exercises at the end of each chapter. The idea of the ring, the concept of Hausdorff space, Banach's fixed point theorem, the Euler characteristic of a complex, and Borsuk's theorem on antipodes are topics treated in exercises. Professor Kuratowski has produced here a valuable textbook for students at advanced undergraduate or graduate level.

200 pages

42s. net $(\$ 6.50)$

Pergamon Press has in preparation over 50 new mathematics titles.

Please send for descriptive literature on these and many other published books.

All books gladly sent on 14 days' approval.

\section{PERGAMON PRESS Oxford London New York Paris}

\author{
HEADINGTON HILL HALL, OXFORD
}

4 \& 5 Fitzroy Square, London W.1

122 East 55th Street, New York 22, N.Y 


\section{AIDIDO}

\section{Ẽurational 羽olícy}

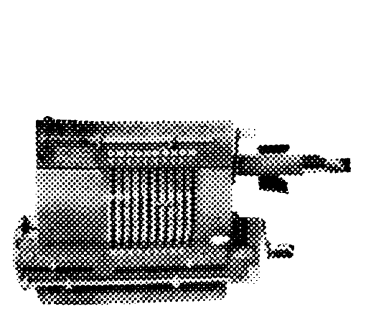

ADDO LIMITED have now assumed the responsibility for carrying out the Policy originally begun by BULMER'S (CALCULATORS) LTD. in January 1960. 'This offers to educational bodies (a) Lecture Demonstrations on Add/listing, Accounting, Calculating, Filing and Indexing (b) Free Loan of machines in conjunction with or instead of the lectures (c) Instruction manuals, tuition etc. (d) Assistance towards the purchase of machines amounting to between $25^{\circ} \circ$ and $33 \frac{1}{3} \%$.

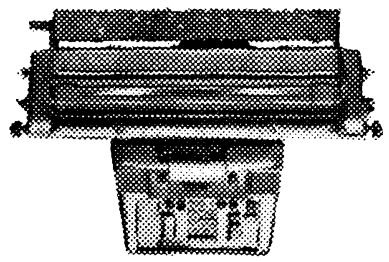

For some time we have felt that no one can legitimately criticise the standard of education of young people leaving schools and colleges unless and until industry and commerce provide education with (a) details of their requirements (b) reasons for these standards (c) know-how on how to achieve these, and (d) some practical help to enable equipment to be made available. This policy is an attempt to fill the gap and help out in the field in which ADDO are most active.

For a full statement of the ADDo

Educational Policy, illustrated literature and prices, please write to

G. Norman Porter, Esq.,

Education \& Training Division

ADDO LIMITED,

47/5I Worship Street, London EC2.

You are invited to discuss this further, and to see the range of equipment available, on Stand 104A, Business Efficiency Exhibition, Olympia, October 3rd-I ith. 


\section{MATHEMATICS: A PRACTICAL APPROACH}

\section{SURVEYING}

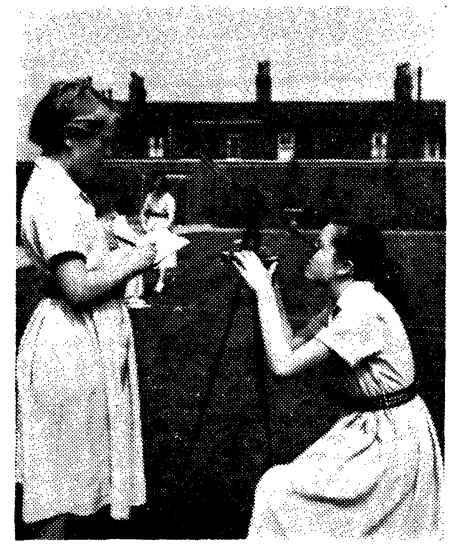

These two girls are surveying the height of the church spire with a home-made theodolite.

PRACTICAL surveying consists of two main branches, both of which deal with two-dimensional problems: land measurements, and the determination of inaccessible heights. In this course of books by P F Burns the computations in both of these branches are at first based on scale drawings; later they are done by spherical trigonometry. Here is an outline of some of the work done in surveying heights in Daily Life Mathematics Books Two, Three and Four.

BOOK TWO Finding the heights of factory chimneys, church spires, high
cliffs and so on, when the heights cannot be measured
directly, by using a gnomon or a geometrical square.

BOOK THREE Using a clinometer to find the angle of elevation of the top of an object, and then either by scale drawing or by calculations involving the use of a table of tangents, calculating the heights in question.

BOOK FOUR Learning how to use a theodolite.

The apparatus needed for surveying and observational work should be made by the pupils themselves. To assist them, workshop drawings and instructions are provided in the text of the books.

\section{DAILY LIFE MATHEMATICS}

To: GINN AND COMPANY LTD., 18 Bedford Row, London, W.C.1. Please send details of Daily Life Mathematics and a loan copy of Book One (11s.6d.) ...... Book Two (10s. 6d.)......Book Three (10s. 6d.)......Book Four (11s. 6d.) ...... Book Five (15s. 6d.).....(Tick what is wanted)

Name

School. 


\section{APPOINTMENTS IN MATHEMATICS}

The University invites applications for permanent or special short-term appointments in the Department of Mathematics as follows.

READER IN APPLIED MATHEMATICS

SENIOR LECTURER IN MATHEMATICAL STATISTICS

\section{SENIOR LECTURER OR LECTURER IN ANY BRANCH OF PURE OR APPLIED MATHEMATICS}

For appointments on a permanent basis, the general conditions of appointment in the University apply.

For special short-term appointments the conditions may, by mutual agreement, provide for return fares from the University after completion of not less than two, nor more than three, years' service. Before these short-term appointments expire they may, by mutual agreement, be made permanent on the normal basis then obtaining. Anyone interested in such an appointment is invited to write to the Registrar and indicate the kind of arrangements that he thinks might be suitable in his case.

Salary scales: Reader £A2950-70-3230; Senior Lecturer $£ A 2450-90-£ 2900$; Lecturer £A1675-95-2340; with superannuation on the F.S.S.U. basis for permanent appointments. The initial salary may be fixed within the appropriate scale in accordance with a successful candidate's qualifications and experience. Salaries are paid monthly.

Further information: The Calendar of the University may be consulted in the Library of any University which is a member of the A.U.B.C. or at the office of the Association. A potential candidate should also seek from the Registrar of the University or from the Secretary, Association of Universities of the British Commonwealth (Branch Office), Marlborough House, Pall Mall, London, S.W.1 copies of the general conditions of appointment for permanent appointments (which include particulars of tenure, superannuation, removal expenses, invalidity and study leave) and of a statement giving further particulars of such matters as help in housing, conference grants and special support for research. Any further information desired will gladly be supplied on request to the Registrar.

Applications, in duplicate and giving the information listed in the final paragraph of the general conditions of appointment, should be sent to the Registrar of the University. There is no formal closing date. 


\section{B L A C K I E}

\section{BOOKS ON MATHEMATICS AT ALL LEVELS}

\section{Differential Equations}

F. G. TRICOMI (Turin)

Translated by E. M. McHARG, PH.D

'In this volume he (the author) has been highly successful in writing a book which is modern and not unduly difficult and which gives the student a clear idea of the most important methods in this field.'

(Dr. Ledermann, The Guardian)

$50 \mathrm{~s}$

\section{Differentiation and Integration}

H. A. THURSTON, M.A., PH.D.

Prof. of Mathematics at the University of British Columbia

A first course in the calculus, by the author of 'The Number System', this book is in line with the modern outlook on the teaching of mathematics which is to encourage the student to think for himself about fundamentals.

30s

\section{Energy Principles in Applied Statics}

T. M. CHARLTON, M.A., B.SC., A.M.I.MECH. E.

University Lecturer in Engineering, Cambridge

deals with the fundamentals of potential energy, virtual work, strain energy and complementary energy methods of analysis .

Presentation is excellent

(The Structural Engineer)

Catalogue \& Prospectuses from: 16-18 William IV Street, London WC2 BLACKIE \& SONS LTD. 
MIDDLESEX COUNTY COUNCIL

EDUCATION COMMITTEE

\section{WILLESDEN TECHNICAL COLLEGE}

Denzil Road, Willesden, London, N.W.10

Principal L. L. Allen, B.Sc. (Eng.), A.K.C., M.I.Mech.E., M.I.E.E., M.I. Prod.E.

The College proposes to offer a two-year part-time day course leading to the DIPLOMA IN MATHEMATICS OF THE MATHEMATICAL ASSOCIATION commencing 18th September, 1961, and requiring attendance on Thursday (first year) and Friday (second year). Minimum entry qualifications are a pass in G.C.E. ' $A$ ' level Pure Mathematics or the successful completion of a third year supplementary Mathematics course at a Training College. Persons with a suitable mathematical background but without the requisite formal qualifications may be admitted to the course at the discretion of the College. Suitably qualified students will be able to study the endorsement subjects Advanced Statistics and/ or Advanced Applied Mathematics during the two-year course.

Further details may be obtained from

Dr. R. H. Rogers, Head of the Department of Electrical Engineering at the College. 


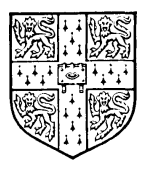

New Mathematics, Part III

\section{K. S. SNELL \& J B. MORGAN}

Three parts of this new unified four-part course are now available. Part III forms a minimum course at ' $O$ ' level for slower pupils, and covers the essential ground for slower streams at secondary schools. Part IV will be ready in 1962. A book of answers to Parts $I$ and II is available (8s. $6 d$.) and for Part III (5s).

'The presentation is most attractive and full of interest. This promises to be a series of rare quality and refreshing originality.' Higher Education Journal.

Parts I and II, each 10s. $6 d$. Part III, 12s. 6d.

\section{New Mathematics: West African Edition, I K. S. SNELL \& J B. MORGAN}

The first part of a special West African edition of this new course is now available. People, places, commodities now have names familiar to West African pupils.

The second part will be ready shortly. Part 1,9 s. $6 d$.

\section{CAMBRIDGE UNIVERSITY PRESS}

BENTLEY HOUSE, 200 EUSTON ROAD, LONDON, N.W.1 


\section{Mathematical Logic}

\section{R. L. GOODSTEIN}

This book represents a rather remarkable contribution to the expository literature of mathematical logic. It is intended for mathematicians with little or no previous knowledge of logic, yet it proceeds to the heart of the subject and describes, clearly and with sufficient detail to be convincing to such persons, some modern results. At the same time it sketches more briefly many other aspects of the subject, so that a reader obtains a surprisingly adequate conception of mathematical logic as a whole.

"The present book paints a picture of mathematical logic; as such it is something of a work of art." The Mathematical Gazette

Demy 8vo. Cloth-bound. viii +104 pp. 2nd Edition. 21s. net

\section{Axiomatic Projective Geometry}

\section{R. L. GOODSTEIN and E. J. F. PRIMROSE}

"The treatment is purely synthetic, and co-ordinates are not used at all. Axioms are introduced as required in the development of the subject; these are conveniently collected for reference on page xi, together with the chapter number in which they are introduced. The authors have succeeded in their task of showing that the subject can be developed rigorously and elegantly, while keeping the arguments at an elementary level." The Mathematical Gazette

„Das letzte Kapitel dieses sehr interessanten Buches, das eine neue Formalisierung der projektiven Geometrie bietet und trotz der formalen Strenge eine ungeheure Fülle von Material auf engem Raum enthält, heisst ,Geometrie als ein Brettspiel' . Hier wird der Nachweis der vollständig formalen Natur des dargestellten Systems geliefert." International Mathematical News

„Kurz und gut, das übliche Programm, aber in korrekter Form zusammengefasst in einem engen Raum. Die Gefahr der Trockenheit ist dabei vollig vermieden. Eine Fülle von Aufgaben mit Lösungen erhöht den Wert des hübschen Büchleins."

Zentralblatt für Mathematik

Demy 8vo. Cloth-bound. xi $+140 \mathrm{pp}$.

15s. net 


\title{
MATHEMATICAL MODELS
}

\author{
SECOND EDITION 1961
}

B Y

\author{
H. MARTYN CUNDY \\ Senior Mathematical Master at Sherborne School
}

AND

\section{A. P. ROLLETT}

This new and enlarged edition gives detailed instructions for making a wide variety of models illustrating elementary mathematics. Nothing of value in the first edition has been omitted: dissections, paper-folding, curve-stitching, the drawing of loci and envelopes, the construction of plane tessellations, polyhedra, and ruled surfaces are all included. Complete plans and nets are given for all regular, Archimedean, and stellated polyhedra, together with compound solids of various kinds. The section on machines has been considerably enlarged, and now includes details of simple electric adding devices and analogue computers. A wholly new chapter has been added on logical devices. Linkages and pendulum machines for drawing lines and curves are described, and the book is fully illustrated with diagrams and plates of models in paper and card, wood and 'Perspex' All the models have been successfully made in school classes or for demonstration.

288 pages, with 4 half-tone plates

and 330 text-figures. 25/-net

\section{OXFORD UNIVERSITY PRESS}




\section{Elementary Statistical Exercises}

\section{F. N. DAVID \& E. S. PEARSON}

A collection of exercises, many of which incorporate tables of numerical data. The book will be valuable to teachers of statistics, undergraduate statisticians and those studying the subject on their own. Ready September.

$13 s .6 d$. net

\section{A Book of Curves}

\section{E. H. LOCKWOOD}

An elementary book on methods of drawing plane curves, including conic sections, cycloidal curves, spirals and 'envelopemethods' written primarily for school libraries and teachers. 25 full-page plates; 90 diagrams. Ready October.

25s. net

\section{New Mathematics}

\section{K. S. SNELL \& J. B. MORGAN}

The first three volumes of this four-volume course are now available. The course covers four years at Secondary School level, taking the subject to G.C.E. ' $O$ ' level standard, and is designed to show the essential unity of the subject.

Volumes I and II, each 10s. $6 d$.

Volume III, 12s. 6 d.

\section{A Book of Graphs}

\section{A. BROWN}

A book to help children to read information from a graph of statistics. They are required to do this in certain examinations, in the course of their studies, and for following current affairs in the newspapers and on television.

$2 s .3 d$. 


\section{Just Published \\ HOMOGENEOUS COORDINATES}

by C. V. DURELL, M.A. 212 pages. 14s. Key, 6s. net.

This book is a sequel to the author's recent and highly praised Elementary Coordinate Geometry. It bridges the gap between G.C.E. scholarship level and the requirements for mathematical scholarships at the Universities.

The range of the book is much the same as that of the author's Algebraic Geometry but the subject-matter is presented here in a simplified and far less detailed form. Brief Contents: Point-coordinates in Cartesian Geometry. Linecoordinates in Cartesian Geometry. The Projective Transformation. Duality. Homography and Involution. Theorems of Chasles and Pascal. Homography and Involution on a Conic. Desargues' Theorem. Triangle and Conic. Reciprocation. Projective and Cartesian Geometry.

\section{MATHEMATICS IN YOUR WORLD}

by KARL MENNINGER. Illustrated. 2Is. net.

This is a book to help readers to widen their mathematical horizons rather than to teach the techniques of mathematics. It is a book for reading and not a textbook. Most of the author's topics are commonplaces in standard mathematical syllabuses but they are here presented afresh and made clear with a wealth of ingenuity and decked with the sparkle of humour. A book for every school library and for teachers' personal reading.

A Recent Success

\section{MATHEMATICAL PUZZLES AND DIVERSIONS}

by MARTIN GARDNER. Demy 8vo. 17s 6d. net. 